\title{
Photoluminescent And Self-Assembled Hyaluronic Acid-Zinc Oxide-Ginsenoside Rh2 Nanoparticles And Their Potential Caspase-9 Apoptotic Mechanism Towards Cancer Cell Lines
}

This article was published in the following Dove Press journal:

International Journal of Nanomedicine

\author{
Yeon Ju Kim ${ }^{1}$ ** \\ Haribalan Perumalsamy ${ }^{1} *$ \\ Verónica \\ Castro-Aceituno (iD) \\ Donghyuk Kim² \\ Josua Markus $\mathbb{D}^{\prime}$ \\ Seungah Lee ${ }^{3}$ \\ Sung $\operatorname{Kim}$ (ID $^{4}$ \\ Ying Liu $\mathbb{D}^{\prime}$ \\ Deok Chun Yang' \\ 'Department of Oriental Medicinal \\ Biotechnology and Graduate School of \\ Biotechnology, College of Life Science, \\ Kyung Hee University, Yongin-si, \\ Gyeonggi-do, Republic of Korea; ${ }^{2}$ School \\ of Energy and Chemical Engineering/ \\ School of Biological Sciences, Ulsan \\ National Institute of Science and \\ Technology (UNIST), Ulsan, South Korea; \\ ${ }^{3}$ Department of Applied Chemistry and \\ Institute of Natural Sciences, College of \\ Applied Science, Kyung Hee University, \\ Seoul, Republic of Korea; ${ }^{4}$ Center for \\ Global Converging Humanities, Kyung \\ Hee University, Seoul, Republic of Korea \\ *These authors contributed equally to \\ this work
}

Correspondence: Yeon Ju Kim

College of Life Sciences, Kyung Hee University, 1732, Deogyeong-daero,

Giheung-gu, Yongin-si, Gyeonggi-do

17104, Republic of Korea

Tel +82 3I 20I 2645

Fax +82 3I 2048116

Email yeonjukim@khu.ac.kr
Background: Zinc oxide nanoparticles (ZnO NPs) are used in modern cancer therapy based on their specific target, efficacy, low toxicity and biocompatibility. The photocatalytic performance of Zinc oxide $(\mathrm{ZnO})$ nanocomposites with hyaluronic acid (HA) was used to study anticancer properties against various human cancer cell lines.

Methods: Zinc oxide $(\mathrm{ZnO})$ nanocomposites functionalized by hyaluronic acid (HA) were prepared by a co-precipitation method (HA-ZnONcs). The submicron-flower-shaped nanocomposites were further functionalized with ginsenoside Rh2 by a cleavable ester bond via carbodiimide chemistry to form Rh2HAZnO. The physicochemical behaviors of the synthesized $\mathrm{ZnO}$ nanocomposites were characterized by various analytical and spectroscopic techniques. We carried out 3-(4, 5-dimethylthiazol-2-yl)-2, 5-diphenyl tetrazolium bromide (MTT) assay to evaluate the toxicity of Rh2HAZnO in various human cancer cells (A549, MCF-7, and HT29). Furthermore, to confirm the apoptotic effects of Rh2HAZnO and to determine the role of the Caspase-9/p38 MAPK pathways by various molecular techniques such as RT-PCR and Western blotting. Furthermore, Rh2HAZnO induced morphological changes of these cell lines, mainly intracellular reactive oxygen species (ROS) were observed by ROS staining and nucleus by Hoechst staining.

Results: We confirmed that Rh2HAZnO exhibits the anti-cancer effects on A549 lung cancer, HT29 colon cancer, and MCF7 breast cancer cells. Moreover, intracellular reactive oxygen species (ROS) were observed in three cancer cell lines. Rh2HAZnO induced apoptotic process through p53-mediated pathway by upregulating p53 and BAX and downregulating BCL2. Specifically, $\mathrm{Rh} 2 \mathrm{HAZnO}$ induced activation of cleaved PARP (Asp214) in A549 lung cancer cells and upregulated Caspase-9/phosphorylation of p38 MAPK in other cell lines (HT29 and MCF-7). Furthermore, $\mathrm{Rh} 2 \mathrm{HAZnO}$ induced morphological changes in the nucleus of these cell lines.

Conclusion: These results suggest that the potential anticancer activity of novel $\mathrm{Rh} 2 \mathrm{HAZnO}$ nanoparticles might be linked to induction of apoptosis through the generation of ROS by activation of the Caspase-9/p38 MAPK pathway.

Keywords: zinc oxide nanocomposites, ginsenoside Rh2, Dendropanax morbifera Léveille, cytotoxicity, anticancer activity, drug delivery

\section{Introduction}

The Global Cancer Observatory estimates of the incidence of mortality and prevalence from major types of cancers such as lung, breast, and liver for 184 countries of the world revealed that there were 14.1 million new cancer cases, 8.2 million 
cancer deaths, and 32.6 million people living with cancer. ${ }^{1}$ By 2030 , it is projected that there will be 26 million new cancer cases and 17 million cancer deaths per year. ${ }^{2}$ Besides, during the last decade, novel synthetic chemotherapeutic agents currently used for the treatment of cancer have not succeeded in fulfilling expectations despite the considerable cost of their development. Consequently, there is constant demand to develop new, target-specific, and affordable anticancer drugs. ${ }^{3}$

Nanomedicine is the field of biomedical application of nanotechnology in which contrived nanoparticles (NPs) are used to treat diseases. ${ }^{4}$ Nanomedicine, with its innovative imaging and therapeutic competencies, has the prospective for early detection of cancer and cancer treatment. ${ }^{5}$ Nanomaterials can also be functionalized with biomolecules, to ensure target specificity, increasing the biocompatibility and characteristic of multifunctional. ${ }^{6}$ $\mathrm{ZnO}$ nanoparticles are nano-sized (less than $100 \mathrm{~nm}$ ) particles and have a wide range of biomedical application such as cosmetics and facial products. ${ }^{7} \mathrm{ZnO}$ nanoparticles are now being extensively researched for their anticancer properties. The effect of $\mathrm{ZnO}$ on the cytotoxic and apoptotic mechanism by releasing $\mathrm{ZnO}$ materials which induce cell death and it also suggest that requirement for $\mathrm{ZnO}$ dissolution for effective cytotoxicity. ${ }^{8}$ The main bioactive components of ginseng are triterpenoids collectively classified as ginsenosides. Among these ginsenosides, the metabolites of protopanaxadiol (PPD)-type ginsenosides are predominantly transformed into compound $\mathrm{K}$ (CK) and ginsenoside $\mathrm{Rh} 2 .{ }^{9}$ These minor ginsenosides often exhibit superior pharmacological effects compared to their precursors. ${ }^{10}$ However, their clinical application is significantly limited due to their hydrophobic saponin backbone, poor bioavailability and absorption, and nontargeted cytotoxicity to normal cells. ${ }^{11}$ So biomolecular conjugations of ginsenosides with $\mathrm{ZnO}$ and drug delivery techniques play a significant role in solving these problematic issues. ${ }^{12}$

Zinc is an obligatory trace element for humans and plays an important role in regulating cellular metabolism. The Food and Drug Administration (FDA) included $\mathrm{ZnO}$ in the list of generally recognized as a safe (GRAS) material based on their biodegradable, less toxic and easily absorbed by the body. ${ }^{13}$ Previous research stated that photocatalytic or photoluminescent effect of ZnONPs under light irradiation can produce reactive oxygen species (ROS) such as hydroxyl radicals and hydrogen peroxide which enable cell death and efficient decomposition of organic compounds. ${ }^{14}$ The objective of this study is to develop zinc oxide nanocarriers with ginsenoside by green synthesis. Zinc oxide nanoparticles help improve water dispersibility (poorly water-soluble ginsenosides), stability, and therapeutic effect agents that may elevate their capacities as effective anticancer agents. Zinc oxide $(\mathrm{ZnO})$ nanocomposites functionalized by hyaluronic acid (HA) were prepared by a co-precipitation method (HA-ZnONcs), and the physiochemical properties of Rh2HAZnO were well characterized by spectroscopic analysis. In this study, we evaluated the potential effect of Rh2HAZnO nanoparticles to induce apoptotic-medicated cell death by damaging the nucleus and its materials in various human cancer cell lines, such as lung cancer (A549) cells, colon cancer (HT29) cells, and breast cancer (MCF7) cells. Elucidation of the effect of Rh2HAZnO on Caspase-9/p38 MAPK mediated pathway through upregulation of the gene and proteins by anticancer activity.

\section{Experimental Section Materials And Methods}

The leaves of six-year-old Dendropanax morbifera Léveille and ginsenoside Rh2 ( $\geq 90 \%)$ were acquired from Ginseng Bank, Kyung Hee University (Yongin, Republic of Korea). High-molecular-weight sodium hyaluronate (HA, $\mathrm{M}_{\mathrm{W}}=1,280 \mathrm{kDa}$ ) was supplied by Xinjiang Fufeng Biotechnologies Co., Ltd. (Xinjiang, China). Zinc nitrate hexahydrate (reagent grade, $\geq 98 \%$ ), $N$-(3-dimethylaminopropyl)- $N$ '-ethylcarbodiimide hydrochloride (EDC, reagent grade, $\geq 98 \%$ ), 4-(dimethylamino) pyridine (DMAP, $\geq 99 \%$ ), hydrochloric acid ( $\mathrm{HCl}$, ACS reagent, $37 \%$ ), and anhydrous $N, N$-dimethylformamide (DMF, $\geq 99 \%$ ) were purchased from Sigma-Aldrich Chemicals (St. Louis, MO, USA). Phosphate buffer (20× PBS) was purchased from Biosesang (Seongnam, Republic of Korea). Trichloroacetic acid (TCA, $\geq 99 \%$ ), potassium persulfate ( $\geq 98 \%$ ), potassium ferricyanide ( $\geq 98 \%$ ), sodium chloride $(\mathrm{NaCl}, \geq 99.50 \%$ ), and sodium hydroxide $(\mathrm{NaOH}$, $\geq 98 \%$ ) were purchased from Daejung Chemicals and Metals Co., Ltd. (Siheung, Republic of Korea). Glycerol was purchased from Junsei Chemical Co., Ltd (Tokyo, Japan). Iron (III) chloride hexahydrate (97\%), methyl alcohol $(\mathrm{MeOH}, 95 \%)$, and ethyl alcohol (EtOH, 95\%) were procured from Samchun Pure Chemical Co. Ltd. (Pyeongtaek, Republic of Korea). Other chemicals and reagents were purchased from commercial suppliers. 


\section{Synthesis And Characterization Of $\mathrm{Rh} 2 \mathrm{HAZnO}$}

Synthesis of hyaluronic acid-functionalized $\mathrm{ZnO}$ (Rh2HAZnO) nanoparticle was prepared as per our previous study. ${ }^{12}$ The hyaluronic acid-functionalized $\mathrm{ZnO}$ was prepared by a $\mathrm{NaOH}$-assisted co-precipitation method using zinc nitrate hexahydrate as a salt precursor and polymers as steric stabilizing agents. Aqueous leaf extract of $D$. morbifera was incorporated in the synthesis to enhance water stability and was synthesized as in a previous study, and the physiochemical properties were analyzed and reported. ${ }^{15}$ For characterization of nanoparticles, we have used scanning electron microscopy (SEM), and elemental mapping was performed. The previous study includes spectrophotometry (UV-Vis), field emission-transmission electron microscopy (FE-TEM), X-ray diffraction (XRD), zeta potential and hydrodynamic particle size of nanocomposites, and Fourier-transform infrared (FTIR) spectroscopy. Drug loading content of Rh2HAZnO was quantified by liquid chromatography-mass spectrometry (LC-MS), approximately $0.32 \mu \mathrm{g}$ of ginsenoside $\mathrm{Rh} 2$ per $1 \mathrm{mg}$ of Rh2-HA-ZnONcs was detected.

\section{Photoluminescence Spectra}

The photoluminescence (PL) spectra were measured at room temperature using the $325-\mathrm{nm}$ line of a $\mathrm{HeCd}$ laser as the excitation source. Emitted light was collected by a lens and analyzed using a grating monochromator and a GaAs photomultiplier tube. Standard lock-in detection techniques were used to maximize the signal-to-noise ratio. The laser power for the PL excitation was about $5.66 \mathrm{~W} / \mathrm{cm}^{2}$.

\section{Total Internal Reflection Scattering (TIRS)}

The schematic representation and physical layout of the apparatus were modified from previously published protocols. ${ }^{16}$ The TIRS microscopy was carried out with upright Olympus BX51 microscope (Olympus Optical Co., Ltd., Tokyo, Japan) equipped with a $100 \times$ oil iris objective lens (NA $=0.6-1.3$, UPLANFLN, Olympus Optical Co., Ltd., Tokyo, Japan). The smallest NA value (i.e., 0.6) was used for all the experiments. TIR illumination was conducted with a 30-mW, 637-nm laser (MGL-III-637-200 $\mathrm{mW}$, Changchun New Industries Optoelectronics Tech. Co., Ltd., China) for illumination of the gold nanoparticles. A Uniblitz mechanical shutter (model LS3S2ZO-R3, Vincent Associates, Rochester, NY, USA) and a driver (model VMM-D1, Vincent Associates) were synchronized to an electron-multiplying cooled charge-coupled device $($ EMCCD) camera $(512 \times 512$ pixel imaging array, QuantEM 512SC, Tucson, AZ, USA). The exposure time was $100 \mathrm{~ms}$. Wavelength selection was accomplished with a central wavelength of $620 / 14 \mathrm{~nm}$ on an instrument purchased from Semrock (Rochester, NY, USA).

\section{Cell Lines}

Human lung carcinoma (A549), human colon carcinoma (HT29), breast cancer (MCF7) cell lines and normal human keratinocytes (HaCaTs) were purchased from the American Type Culture Collection (ATCC) (Manassas, VA, USA). All cell lines were grown in RPMI 1640 medium supplemented with $10 \%$ fetal bovine serum and $1 \%$ penicillin and streptomycin, at $37{ }^{\circ} \mathrm{C}$ in $5 \% \mathrm{CO}_{2}$.

\section{Cell Viability Assay}

The cell cytotoxicity of Rh2HAZnO toward the various human cancer cell lines (A549, HT29, and MCF-7) was evaluated using an MTT assay. MTT stock solution $(10 \times)$ $(5 \mathrm{mg} / \mathrm{mL}$ ) was dissolved in phosphate-buffered saline (PBS) $\left(\mathrm{pH}\right.$ 7.4), filter sterilized and stored at $-20{ }^{\circ} \mathrm{C}$. We used $2 \times 10^{4}$ cells per well (96-well plates) containing $100 \mu \mathrm{L}$ of the complete culture medium. After $24 \mathrm{hrs,} \mathrm{the} \mathrm{test} \mathrm{samples}$ of different concentrations were added onto 96-well plates. The final concentration of DMSO Hybri-Max in all assays was less than $0.1 \%$. Based on the preliminary test results, the anti-proliferative activity of $\mathrm{Rh} 2 \mathrm{HAZnO}$ was determined with five to six concentrations ranging from 0 to $200 \mu \mathrm{g}$ in $0.1 \%$ DMSO. The culture plates were incubated for 2 days in a $37^{\circ} \mathrm{C}$ supplied with a humidified atmosphere of $5 \% \mathrm{CO}_{2}$. The plates were then washed with $100 \mu \mathrm{L}$ PBS, and $0.05 \%$ of $100 \mu \mathrm{L}$ MTT reagent was added to each well and then incubated for $4 \mathrm{hrs}$ as stated previously. MTT solution was removed, and $200 \mu \mathrm{L}$ DMSO was added to each well. Finally, the plate was shaken in a microplate shaker for 10 mins in dark condition to dissolve the purple formazan crystals. The DMSO solution is used as a negative control. The optical density values were recorded using a VersaMax microplate reader (Molecular Devices, Sunnyvale, CA, USA) at a $560 \mathrm{~nm}$ and $670 \mathrm{~nm}$, respectively. Blank values were subtracted from experimental values.

\section{Reactive Oxygen Species (ROS) Generation}

Free radical scavengers were analyzed by DPPH method, and intracellular ROS was measured by 
2',7'-dichlorodihydro-fluorescein diacetate (DCFH-DA), as previously described. ${ }^{8}$ In brief, all three cell lines $\left(2 \times 10^{5} /\right.$ well $)$ were treated with different concentrations of $\mathrm{Rh} 2 \mathrm{HAZnO}(10$ and $20 \mu \mathrm{g} / \mathrm{mL}$ ) for $24 \mathrm{hrs}$. Then, $100 \mu \mathrm{L}$ of DCFH-DA was added at $25 \mu \mathrm{M}$ and incubated for 30 mins. Next, media were discarded and cells were washed twice with $1 \times$ PBS. The supernatant was kept in a 96-well plate in the dark, and the fluorescence intensity was determined with a spectrofluorometer with excitation at $485 \mathrm{~nm}$ and emission at $520 \mathrm{~nm}$.

\section{Apoptosis Detection}

Hoechst-33258 staining was performed to capture the apoptotic induction of Rh2HAZnO in A549, HT29, and MCF7 cells. Cells were seeded into a 6-well plate at a density of $1 \times 10^{5}$ cells/well in $2 \mathrm{~mL}$ medium and incubated at $37{ }^{\circ} \mathrm{C}$ with $5 \% \mathrm{CO}_{2}$ overnight. The cells were then treated for $48 \mathrm{hrs}$ and then stained with Hoechst33258 solution at $2 \mu \mathrm{g} / \mathrm{mL}$ for 20 mins following our previous protocol. Scale bars were added using ImageJ software.

\section{Quantitative Real-Time Reverse Transcription-PCR Analysis}

Treated and non-treated cultures of A549, HT29, and MCF7 cell monolayers grown in $25-\mathrm{cm}^{2}$ cell culture flasks (Corning Costar, NY, USA) were treated with different concentrations of Rh2HAZnO $(\mu \mathrm{g} / \mathrm{mL})$. After $24 \mathrm{hrs}$ of treatments, the total RNA was extracted from non-treated and treated cultures using the RNeasy mini kit (Qiagen, Hilden, Germany). For Real-time quantitative PCR (qRTPCR), 500 ng of total RNA was reverse transcribed using oligo (dT) 15 primer $(0.2 \mathrm{mM})$, and AMV Reverse Transcriptase (10 units/ $\mu \mathrm{L}$ ) and cDNA were synthesized using Superscript First-Strand Synthesis Kit (Invitrogen, Carlsbad, CA) according to the manufacturer's instructions. qRT-PCR was performed in 96-well plate using $100 \mathrm{ng}$ of cDNA in a $20 \mu \mathrm{L}$ reaction volume using SYBR ${ }^{\circledR}$ Green Sensimix Plus Master Mix (Quantace, Watford, England). The melting point analysis of PCR products was carried out, which resulted in a single peak, indicating the presence of a single PCR product amplification. The thermal cycler conditions recommended by the manufacturer were used as follows: $10 \mathrm{mins}$ at $95{ }^{\circ} \mathrm{C}$, followed 40 cycles of $95{ }^{\circ} \mathrm{C}$ for $10 \mathrm{~s}, 58{ }^{\circ} \mathrm{C}$ for $10 \mathrm{~s}$, and $72{ }^{\circ} \mathrm{C}$ for $20 \mathrm{~s}$. The fluorescent product was detected at the last step of each cycle and measured in the real-time reverse transcriptase PCR thermocycler, and its genomic increase of the fluorescence corresponding to the exponential increase of the product was used to determine the threshold cycle $(\mathrm{Ct})$ in each reaction using the formula $2-\Delta \Delta \mathrm{Ct}$ (Livak \& Schimittgen, 2001). The housekeeping gene encoding $\beta$-actin was used as a standard for all samples. All the real-time experiments were performed in triplicates, and statistical analysis was determined using Student's $t$-test.

\section{Western Blotting}

Three human cancer cell lines $\left(2 \times 10^{5} /\right.$ well $)$ were treated with different concentrations $(\mu \mathrm{g} / \mathrm{mL})$ of Rh2HAZnO 0.1 $\mathrm{mL}$ DMSO for about $24 \mathrm{hrs}$. The cells were then harvested and washed twice with cold PBS. The cell pellets were lysed using RIPA lysis buffer (Sigma-Aldrich). The controls received $0.1 \%$ DMSO. The lysates were then centrifuged at $12,000 \mathrm{rpm}$ for $20 \mathrm{mins}$ at $4{ }^{\circ} \mathrm{C}$. The protein content of the supernatant was determined using a Bradford Protein Assay kit, and BSA was used as the standard. The total proteins $(15 \mu \mathrm{g})$ were mixed with an equal volume of $5 \times$ sample buffer containing $40 \mathrm{mM}$ of DL-dithiothreitol, boiled for $10 \mathrm{mins}$, and then loaded onto $10 \%$ sodium dodecyl sulfate-polyacrylamide gels using a Mini-Protean 3 electrophoresis cell (Bio-Rad, Hercules, CA, USA). After electrophoresis at $150 \mathrm{~V}$ for $1.5 \mathrm{hrs}$, the proteins from the gels were transferred onto a polyvinyl difluoride membrane (Pall Corporation, Pensacola, FL, USA) using an electroblotting apparatus. The membrane was then blocked with 5\% skim milk (BD Difco, Franklin Lakes, NJ, USA) in PBS containing 0.1\% (v/v) Tween-20 (PBS-T) at room temperature for $1 \mathrm{hr}$ and further incubated overnight at $4{ }^{\circ} \mathrm{C}$ with a specific monoclonal or polyclonal antibody stated previously, each of them were used at a dilution of 1:1000 dilution. After washing with $0.1 \%$ PBS-T three times at 10 -min intervals, the membranes were further incubated with a goat anti-rabbit IgG H\&L (HRP) secondary antibody at a 1:5000 dilution for $2 \mathrm{hrs}$ RT. Finally, after washing with $0.1 \%$ PBS-T three times with a 10 -min interval between washes, the blots were developed with an ECL chemiluminescence reagent and immediately exposed to a CP-PU X-ray film (AGFA, Mortsel, Belgium). The differences in protein expression were quantified using a Molecular Imager Gel Doc XR system (Bio-Rad, Hercules, CA, USA) and normalized to actin expression on the same membrane. 


\section{Statistical Analysis}

Results are expressed as mean \pm SEM. The statistical significance of differences between values was evaluated by one-way ANOVA. The statistical analysis was performed using Graph Pad 6.04 software (La Jolla, CA, USA). All experiments were performed at least in triplicate $(n \leq 3)$ unless stated otherwise. Experimental data are reported as the means \pm standard error (SEM). Statistical significances between control and sample groups were evaluated by Student's $t$-test with two-tailed distribution and two-sample equal variances. The extent of statistical significance was assigned by an increasing number of asterisks ( ${ }^{*} \mathrm{P}<0.05, * * \mathrm{P}<0.01$, and $\left.* * * \mathrm{P}<0.001\right)$.

\section{Results And Discussion \\ Characterization Nanoparticles By SEM}

The interactions of HA-ZnO with Rh2, PL spectroscopy was performed for the confirmation of the interaction. Figure 1A shows PL spectra of $\mathrm{Rh} 2, \mathrm{HA}-\mathrm{ZnO}$, and $\mathrm{Rh} 2 \mathrm{HAZnO}$, excited by a 325-nm laser line. The major PL peak of $\mathrm{Rh} 2$ is observed at $\sim 410 \mathrm{~nm}$, and the PL spectrum of $\mathrm{Rh} 2$ ranges widely from 350 to $650 \mathrm{~nm}$. The

A
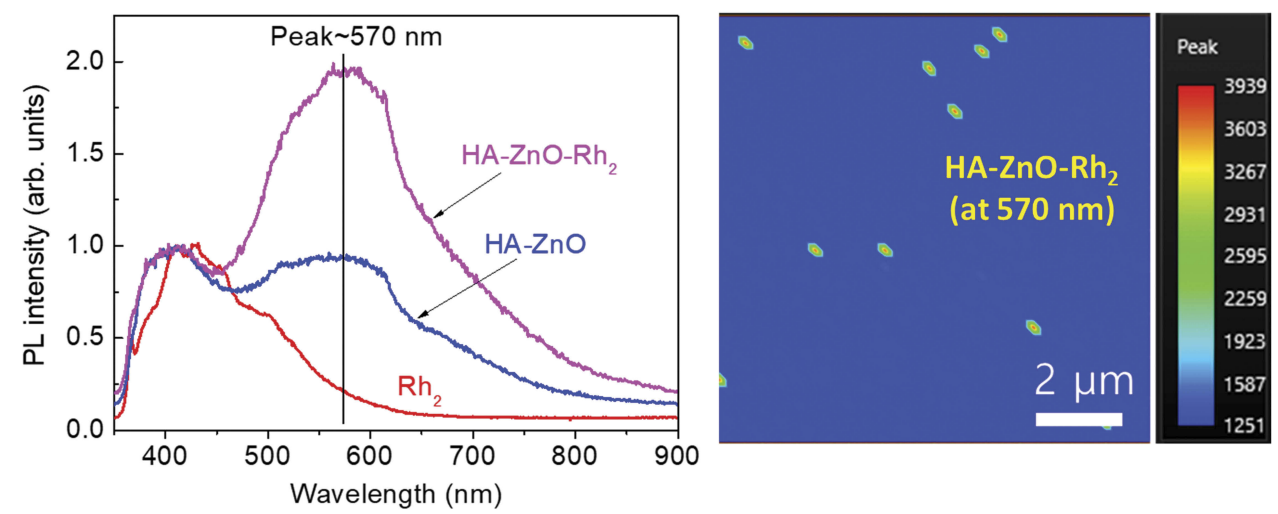

B

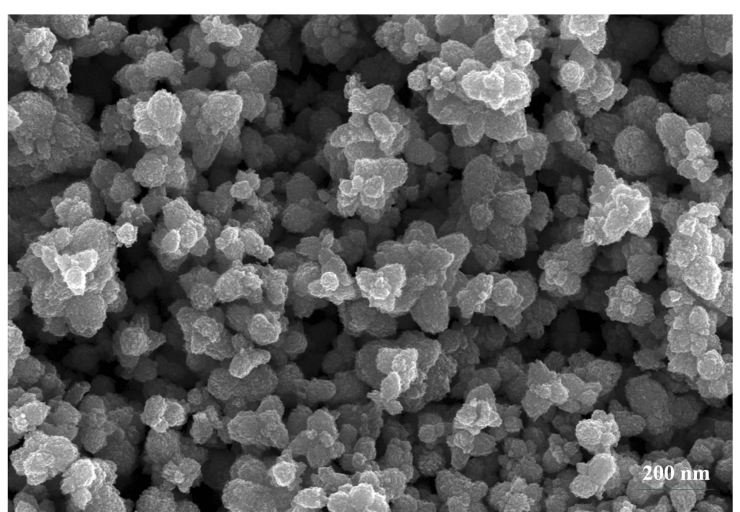

C

Zn Ka1

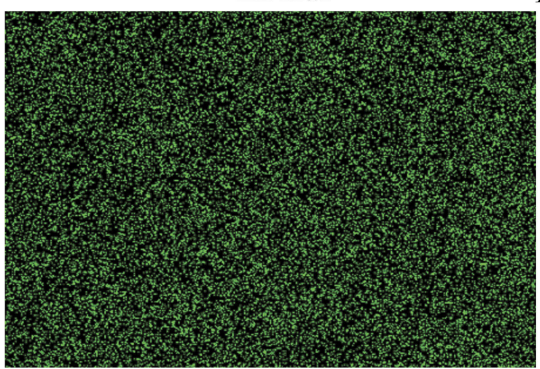

$\mathbf{E}$

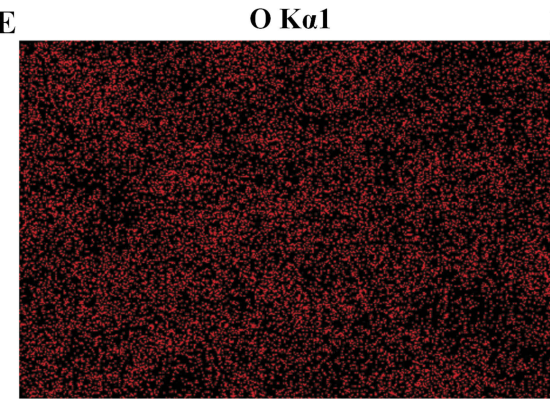

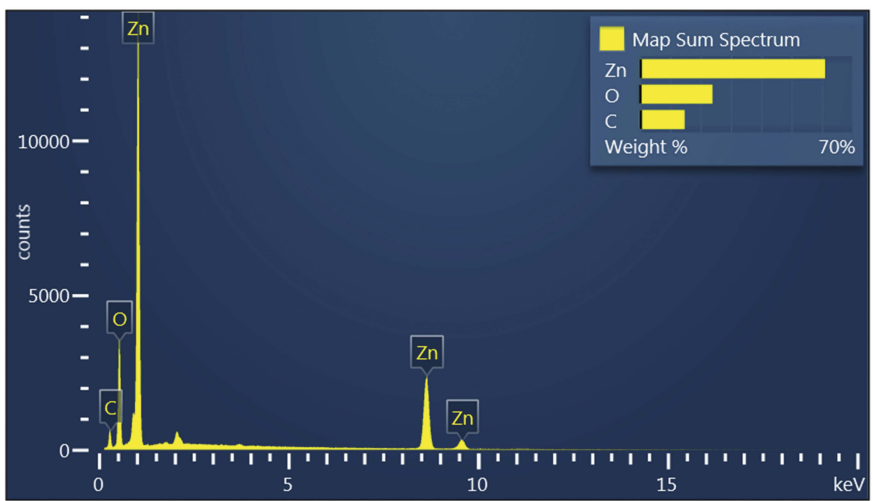

F

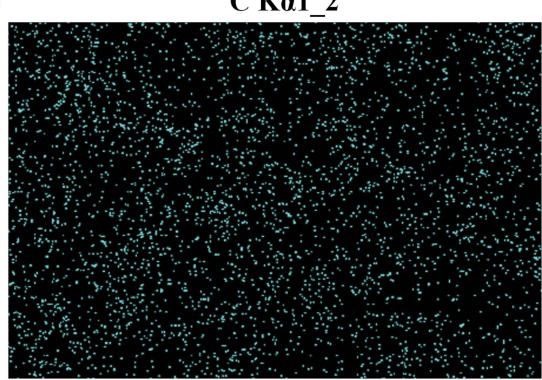

Figure I Characterization of nanoparticles.

Notes: $(\mathbf{A})$ The photoluminescence (PL) spectra were measured at room temperature using the 325-nm line of a HeCd laser as the excitation source. Emitted light was collected by a lens and analyzed using a grating monochromator and a GaAs photomultiplier tube scanning electron microscope (SEM) images. (B) SEM images of $\mathrm{Rh} 2 \mathrm{HAZnO}$. (C) EDS spectrum of complete element distribution. (D-F) Element analytical maps of Zn, oxygen, and carbon. 
PL spectrum of the HAZnO shows a new peak at $570 \mathrm{~nm}$ with a stoke shift of $210 \mathrm{~nm}$, compared to the absorption band at $360 \mathrm{~nm}$, as shown in Figure 1A (absorbance spectrum of HA-Zn nanoparticles). The PL intensity at $570 \mathrm{~nm}$ of HAZnO with $\mathrm{Rh} 2$ ( $\mathrm{Rh} 2 \mathrm{HAZnO}$ ) is increased by about 2 times that of the HAZnO, while the PL intensity at $410 \mathrm{~nm}$ was almost unchanged. This observation means that $\mathrm{HAZnO}$ and $\mathrm{Rh} 2$ interacted with each other (Figure 1A). The surface morphology was analyzed by SEM and revealed that formation of $\mathrm{Rh} 2 \mathrm{HAZnO}$ nanoparticles (Figure 1B). Element mapping confirmed the presence of $\mathrm{Zn}$, oxygen, and carbon (Figure $1 \mathrm{C}-\mathrm{F}$ ).

To develop new anticancer therapies, the study of nanotechnology-based therapies for cancer has been increasing over the years. ${ }^{4}$ Nanotechnology-based therapies circulate in the bloodstream and are undetected by the immune system, which decreases the side effects associated with conventional anticancer treatments. ${ }^{17,18}$ The Rh2HAZnO characterized by X-ray diffraction pattern, FE-TEM, DLS, and FTIR spectra, several functional residues were implicated, such as $\mathrm{O}-\mathrm{H}, \mathrm{C}=\mathrm{O}$ group of esters, $\mathrm{N}-\mathrm{H}$ of amide groups, and $\mathrm{C}-\mathrm{C}=\mathrm{C}$ stretching. The $\mathrm{PL}$ spectra were measured at RT using the 325-nm line of a HeCd laser as the excitation source. Emitted light was collected by a lens and analyzed using a grating monochromator and a GaAs photomultiplier tube. Standard lock-in detection techniques were used to maximize the signal-to-noise ratio. The laser power for PL excitation was about $5.66 \mathrm{~W} / \mathrm{cm}^{2}$. Based on HPLC result, the Rh2HAZnO contained the ginsenoside Rh2 (Figure S1). As the PL value increases, the physical properties such as crystallinity, charge content, and carrierforming ability increased while the transfer of ginsenoside $\mathrm{Rh} 2$ bound to this structure may affect the anticancer activity. $^{19}$

\section{Analysis Of Mitochondria And Nucleus Staining Analysis}

TIRS of Rh2HAZnO, which was used to treat lung cancer A549 cells, is presented in Figure 2A. In the dark field system, Rh2HAZnO accumulated on the cell surfaces after 3 hrs of treatment. Mito-Tracker analysis was performed with or without treatment of Rh2HAZnO for $24 \mathrm{hrs}$ to detect the changes in mitochondria to predict apoptotic cell death-mediated pathway mechanism Figure 2B. At 10 and $20 \mu \mathrm{g} / \mathrm{mL} \mathrm{Rh} 2 \mathrm{HAZnO}$ treated cell lines showed significant bright fluorescence staining with damaged mitochondrial and intracellular debris with prominent stained nucleus indicated that $\mathrm{Rh} 2 \mathrm{HAZnO}$ targeting mitochondrial mediated apoptosis by damaging the outer cellular membrane in A549 cells. Whereas, in control cell lines, there was no significant damage in intracellular organelles which indicated that no or less staining.

\section{In Vitro Cell Cytotoxicity Of Rh2HAZnO}

For evaluation of apoptosis induction and potential antiproliferative effect of this nanoparticle, three different cancer cells were treated with Rh2, HAZnO and Rh2HAZnO for $24 \mathrm{hrs,}$, respectively (Figure 3A-C). A significant reduction in cell viability was observed at 10 $\mu \mathrm{g} / \mathrm{mL}$ in all three cell lines for $\mathrm{Rh} 2 \mathrm{HAZnO}$, respectively (Figure 3D). The reduced systemic toxicity of the drugconjugated nano-formulation can be attributed to the presence of ginsenoside Rh2 in the nanocomposites. Based on the comparison of cell viability in the presence of $\mathrm{Rh} 2$, $\mathrm{HAZnO}$, and Rh2HAZnO in A549 (lung), HT29 (colon), and MCF7 (breast) cancer cells, MCF-7 cell lines were the most inhibited by Rh2HAZnO. We also observed cytotoxicity of HA, Rh2, HAZnO and Rh2HAZnO with normal human keratinocytes (HaCaTs) (Figure 3E).

\section{Intracellular ROS Evaluation In Three Different Cancer Cell Lines}

To analyze the free radical scavenging by the treatment of Rh2HAZnO, DPPH assay was performed. It showed significant changes at $1.5 \mathrm{mg} / \mathrm{mL}$ to compare with positive control gallic acid. For intracellular ROS evaluation, cells were treated with $\mathrm{Rh} 2, \mathrm{HAZnO}$, and $\mathrm{Rh} 2 \mathrm{HAZnO}$ for $24 \mathrm{hrs}$. The increase of ROS was probed by DCFH-DA (Figure 4A-C). Rh2HAZnO from the natural source has been reported to exhibit cell death in various cancer cells (A549, HT29, and MCF-7) through DNA damage by the generation of ROS and activation of multiple pro-apoptotic markers. ${ }^{20,21}$ The feature of ZnONPs is their capability to generate ROS at their surface, which can lead to cell death when the ROS levels exceed the antioxidant capacity of the cell. Therefore, ZnONPs have recently expanded prodigious interest in biomedical applications such as antibacterial and anticancer therapies. ROS generated on the surface of the ZnONPs, and particle dissolution and subsequent release of free $\mathrm{Zn}^{2+}$ ions that lead to ROS production within cells. ${ }^{22}$ Thus, determination of the antiproliferation effect of Rh2HAZnO was done through evaluation of with measurement of ROS level. Intracellular ROS production in cancer cell lines A549 
A

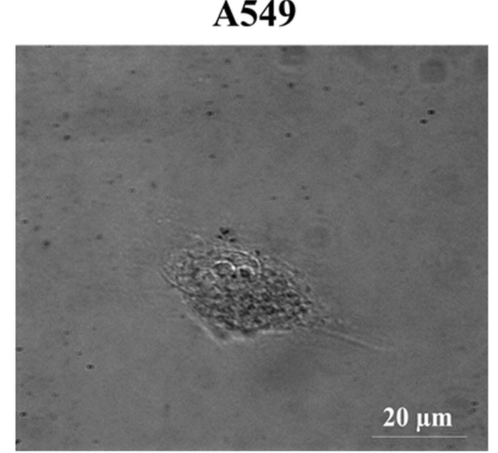

B

Hoechst 33258

Control

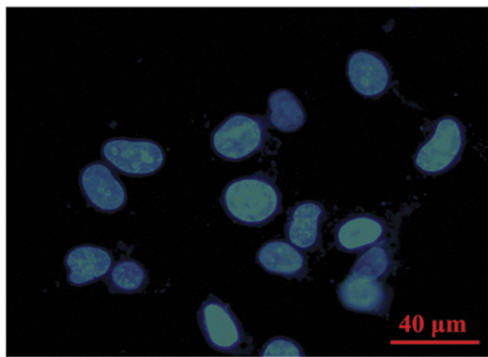

$5 \mu \mathrm{g} / \mathrm{mL}$

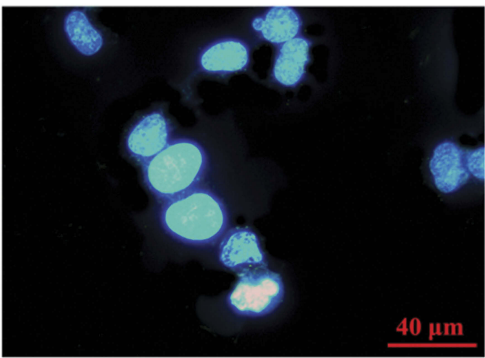

$10 \mu \mathrm{g} / \mathrm{mL}$

$20 \mu \mathrm{g} / \mathrm{mL}$
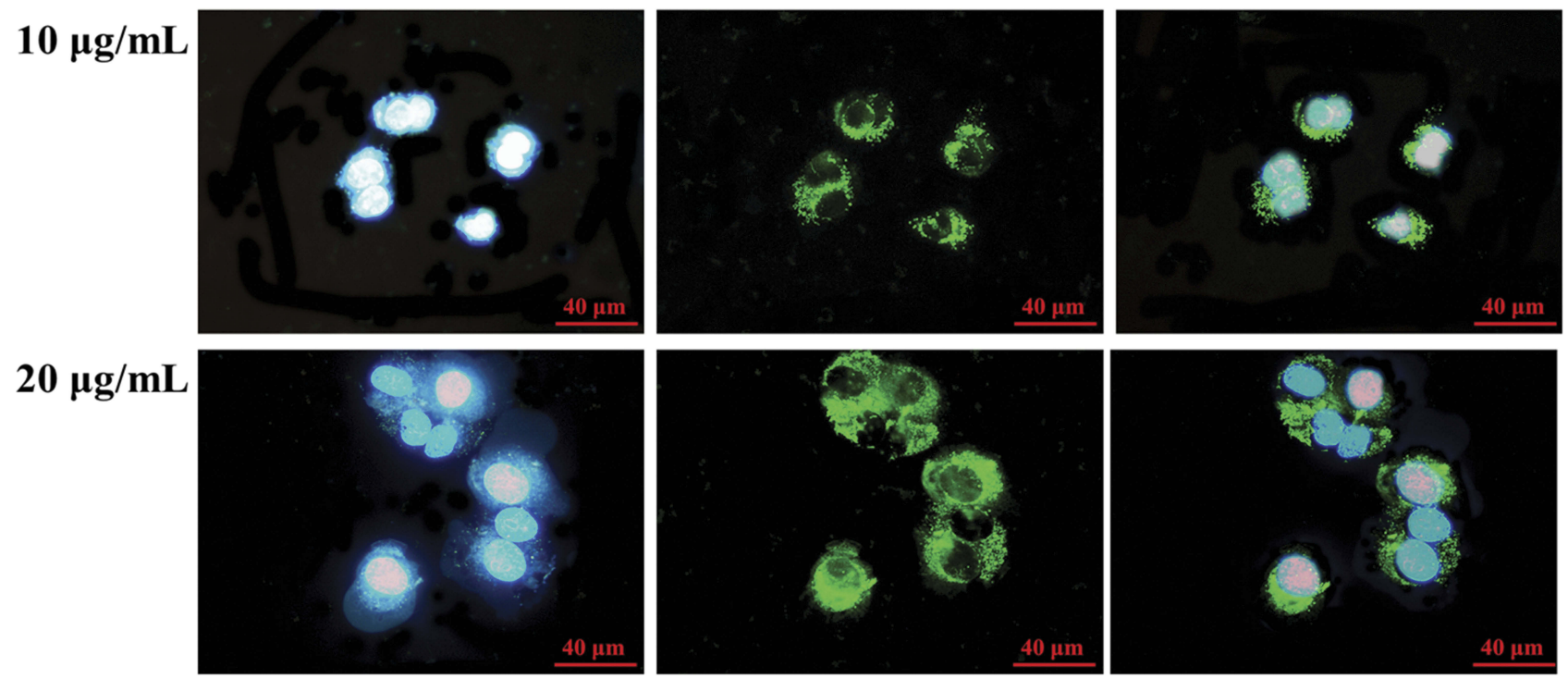

Zinc

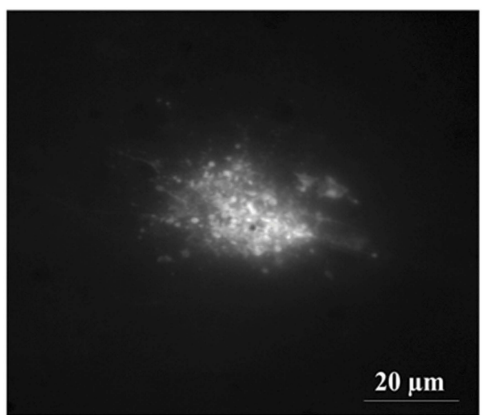

Mito-Tracker
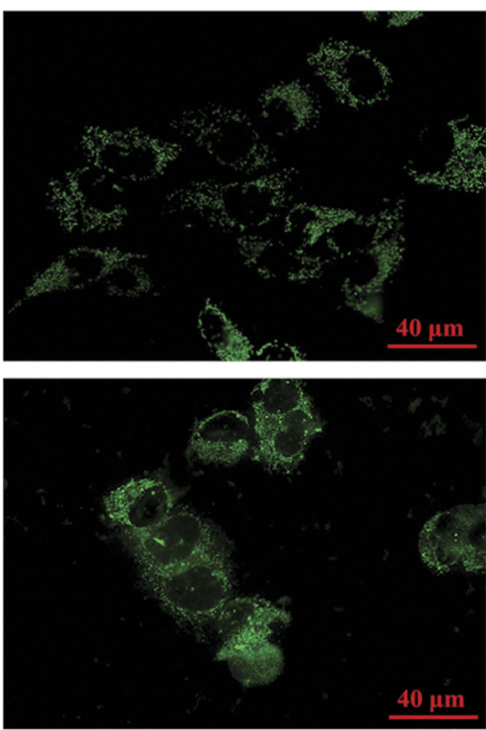
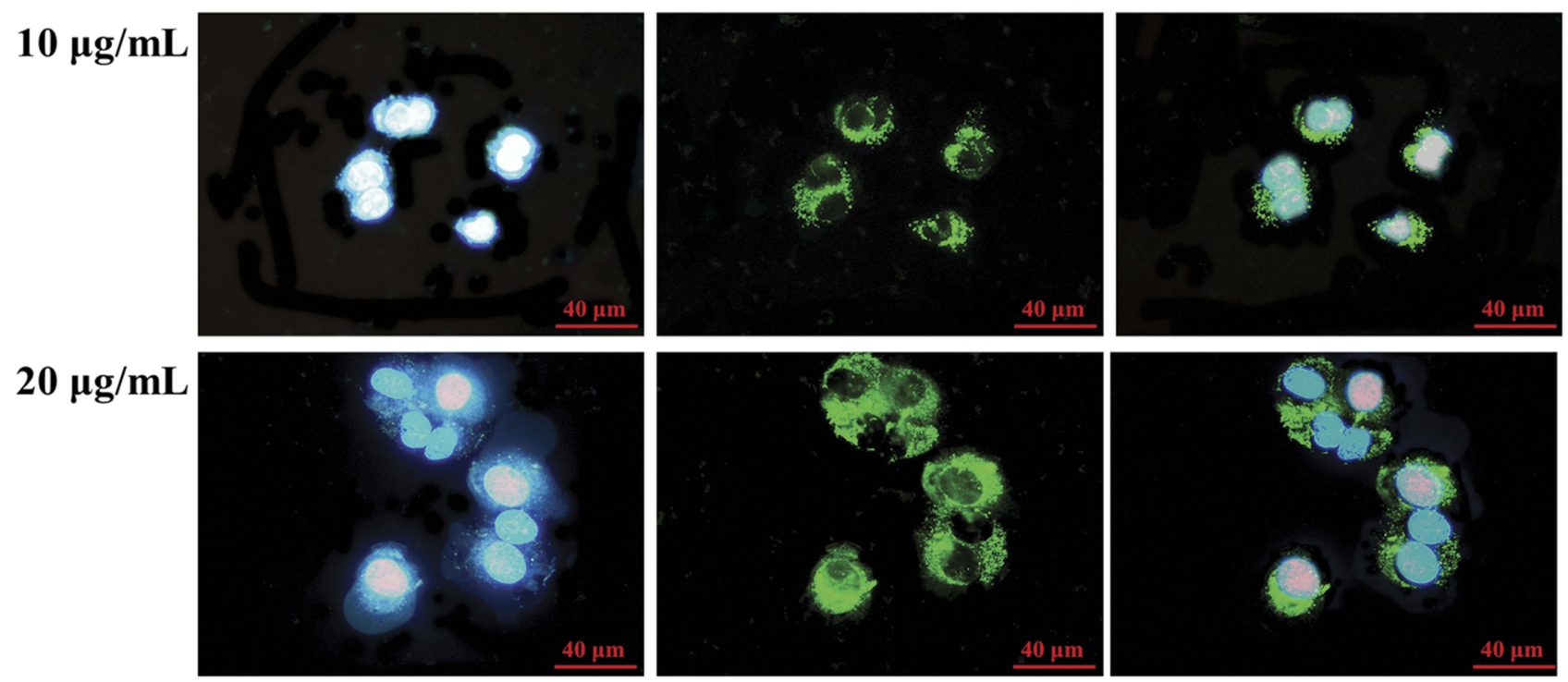

Rh2HA-ZnONP + Cell

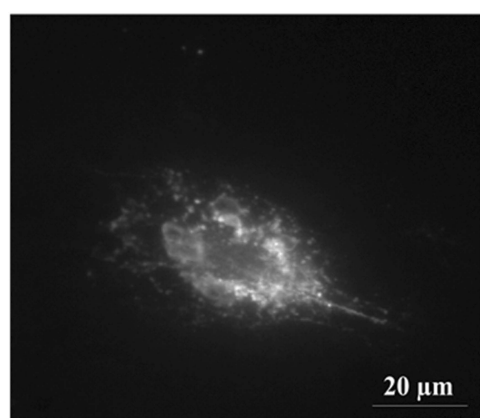

$20 \mu \mathrm{m}$

Figure 2 Total internal reflection scattering images (TIRS) and photoluminescence (PL) spectrum.

Notes: (A) Total internal reflection scattering images (TIRS) of Rh2HAZnO which was treated for lung cancer A549. Lung cancer cell; zinc oxide; cell+ Rh2HAZnO. (B) Mito-Tracker and nucleus staining analysis after the treatment Rh2HAZnO nanoparticles.

(Figure 4A), HT29 (Figure 4B), and MCF7 (Figure 4C) reported the ability of various Rh2HAZnO synthesized was highly related to Rh2HAZnO. Several studies have from natural sources to induce toxicity in cancer cells. 

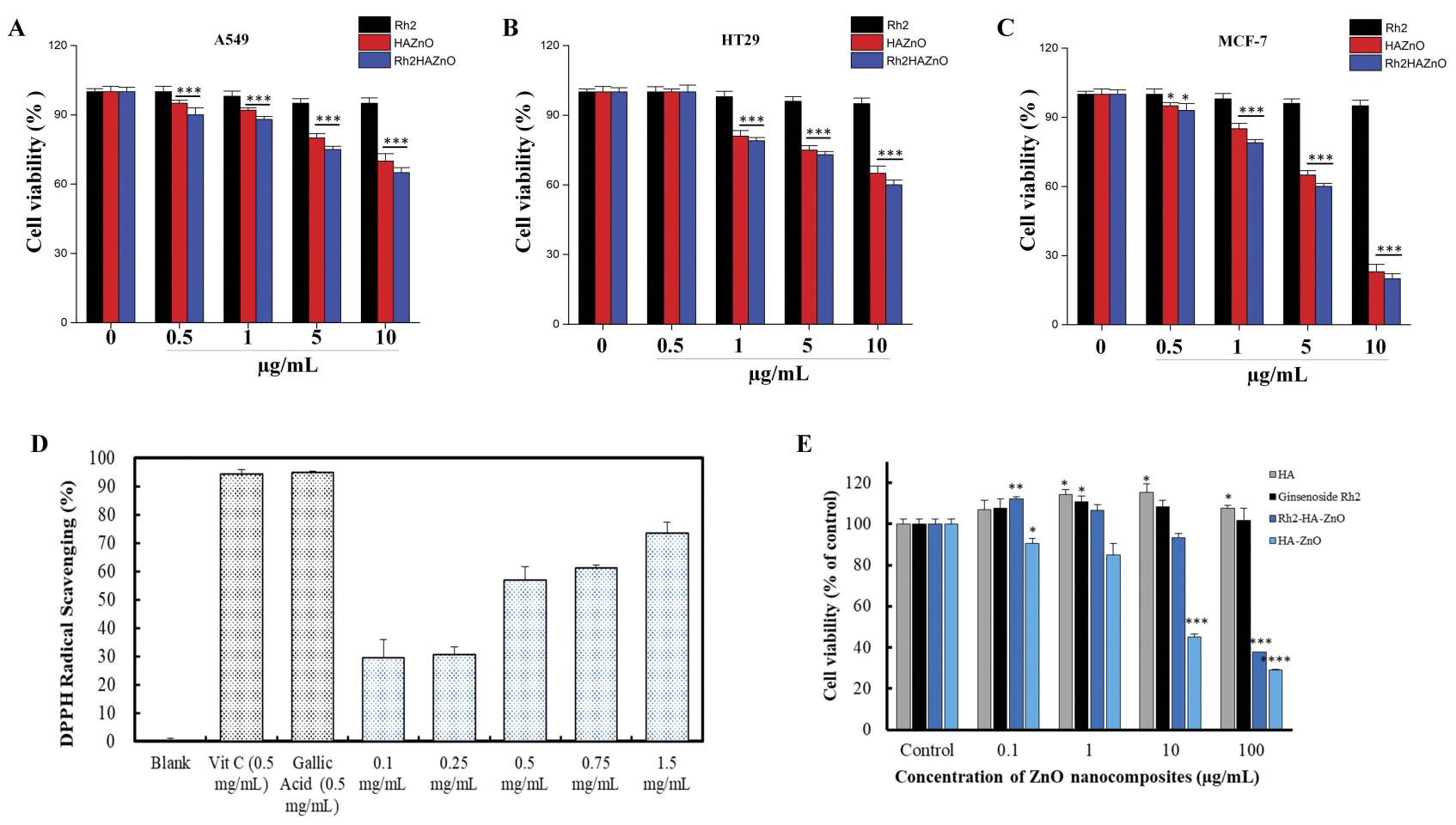

Figure 3 Cytotoxicity evaluation in cancer cells.

Notes: Toxicity evaluation of ginsenoside Rh2, hyaluronic acid zinc nanoparticles (HAZnO), and Rh2HAZnO was assessed by MTT assay after 24 h. (A) Lung cancer (A549). (B) Colon cancer (HT29). (C) Breast cancer (MCF-7). (D) Comparison of cell viability in A549 (lung), HT29 (colon), and MCF7 (breast) cancer cells. (E) The cell viability of normal human keratinocytes (HaCaTs) was examined using MTT assay. Each bar represents the mean $\pm \mathrm{SE}$ of duplicate samples of three independent experiments. $* P<0.05$, $* * P<0.01$, and $* * * P<0.001$ compared to the non-treated control. The difference was observed using Student's $t$-test.

Likewise, the eco-friendly $\mathrm{Rh} 2 \mathrm{HAZnO}$ could induce higher toxicity to cancer cells. Previously, it has been documented that the possible mechanisms of AgNP toxicity include induction of ROS, oxidative stress, DNA damage, and apoptosis in various cell lines. ${ }^{21}$ Oxidative stress is a known mechanism of nanomaterial-induced cell death in various types of cell lines. ${ }^{23}$

\section{Rh2HAZnO Caused Nuclear Damage To Cancer Cells}

A549, HT29, and MCF-7 cancer cells were monitored after different concentrations of Rh2HAZnO treatment by performing Hoechst-33258 staining. In untreated cells, the cell wall remains intact, and the Hoechst dye remains impermeable and thus caused reduced staining of cells. Whereas, when the cells were treated with $\mathrm{Rh} 2 \mathrm{HAZnO}$, the cell walls of cancer cells damaged due to the penetration of the dye into the cells and showed positive apoptotic cells (Figure 5A1, B1, and C1). The results showed that gradual increase in morphological alteration reached its maximum when cells were treated with a high concentration of Rh2HAZnO. In addition, the cell size and number were also significantly reduced, which is evident that $\mathrm{Rh} 2 \mathrm{HAZnO}$ resulted in the detachment of cells and caused alternation in morphology.

\section{Rh2HAZnO Treatment Induced Apoptosis Of Cancer Cells}

Lung cancer (A549), colon cancer (HT29), and breast cancer (MCF-7) cells were treated with Rh2, HAZnO and $\mathrm{Rh} 2 \mathrm{HAZnO}$ to induce nuclear cell death by involving apoptotic mechanism by upregulating the caspase-9/activation of stress-responsive mitogen-activated protein kinases (MAPKs) gene expression such as phosphorylation of p38. The antiapoptotic member, BCL2, and the proapoptotic member, BAX, have been proven to be one of the most critical players in the intrinsic apoptosis pathway. ${ }^{24,25}$ The ratio of $\mathrm{BAX} / \mathrm{BCL} 2$ is a key factor regulating apoptosis. ${ }^{26}$ The ratio BAX/BCL2 significantly increased in both A549 and HT29 cancer cells (Figure 5A3 and B3), while the BAX/BCL2 ratio did not show significant differences in MCF-7 cancer cells (Figure 5C3).

Caspases (cysteine-aspartic acid proteases) play a vital role in the apoptosis process through activation of caspase 

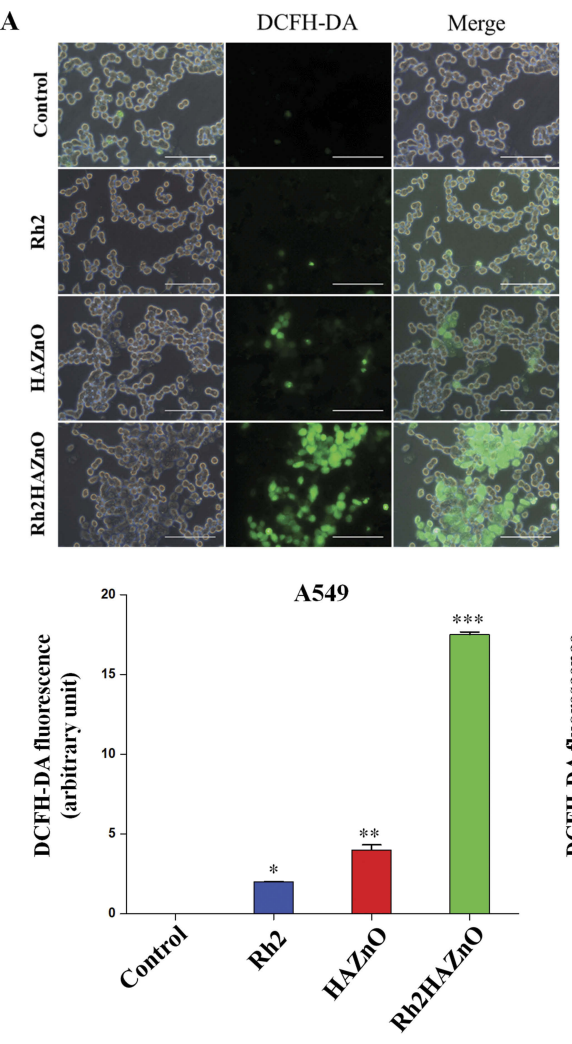
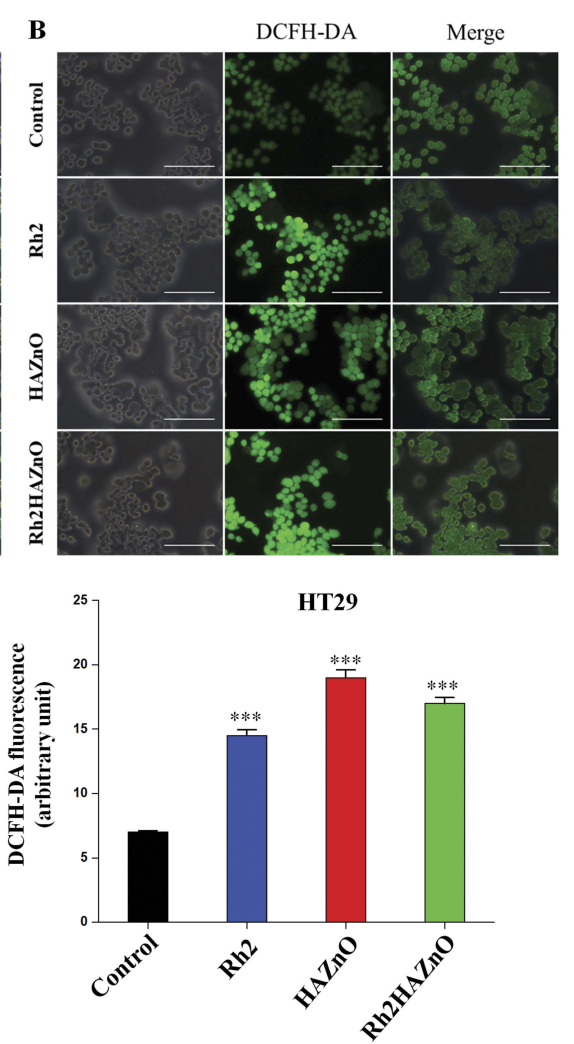
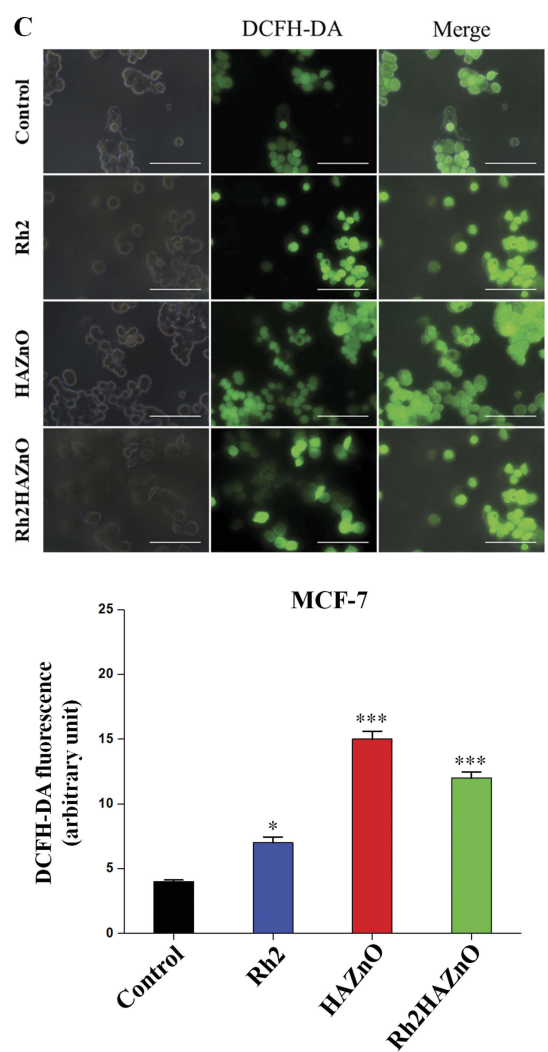

Figure 4 Intracellular ROS evaluation in three cancer cell lines.

Notes: Cells were treated with Rh2 (ginsenoside Rh2), HAZnO (hyaluronic acid zinc oxide nanoparticles) and Rh2HAZnO for 24 hrs, and the increase of ROS was probed by DCFH-DA. Scale bar $=10 \mu \mathrm{m}$. (A) Lung cancer (A549). (B) Colon cancer (HT29). (C) Breast cancer (MCF-7). Each bar represents the mean \pm SE of duplicate samples of three independent experiments. $* P<0.05$, $* * P<0.01$, and $* * * P<0.001$ compared to the non-treated control. The difference was observed using student's $t$-test.

cascades including the initiation of caspase- $9 .{ }^{27}$ A previous study demonstrated that application of pseudo-G-Rh2 induced intrinsic-mediated apoptosis in A549 cells by activation of p53 and caspase-9. ${ }^{28}$ Expression change of p53 correlated with expression change of two downstream BCL2 family proteins, BAX and BCL2. This observation agrees with the transcriptional expression change of p53 in those three cell lines.

The expressions of CASP7, CASP9, and p53 in A549 cell line were analyzed by performing qPCR (Figure 6). The expressions of $C A S P 9$ and $p 53$ genes tend to increase in A549 cells that are gradually with $\mathrm{Rh} 2$ or HAZnO. Moreover, cells treated with $\mathrm{Rh} 2 \mathrm{HAZnO}$ nanoparticles further upregulated both $C A S P 9$ and $p 53$ transcripts (Figure 6C and D). In contrast, the expression of p53 through Western blot analysis did not exhibit increased p53 accumulation, but the cells undergo apoptosis through activation of CASP9 rather than p53 itself (Figure 6D). Expression of the $M A P K$ gene and phosphorylation of the p38 MAPK protein were found no significant difference in A549 cell lines except cleaved PARP (Asp 214) protein.
To determine the potential apoptotic mechanism of Rh2HAZnO in HT29 colon cancer cells, the relative gene expression and the protein expression were assessed. Upon Rh2 treatment, p53 expression was steadily downregulated by up to 0.45 -fold in the HT29 colon cancer cell line. Interestingly, gene and protein expression tend to increase when cells are treated with $\mathrm{HAZnO}$, and the highest expression pattern was recorded when cells were treated with Rh2HAZnO (Figure 7A, E, and G). The expression of p21 was gradually downregulated when cells were treated with Rh2, HAZnO or Rh2HAZnO, which clearly shows that HT29 cells undergo p53-mediated apoptosis (Figure 7). Ginsenosides Rh2 and $\mathrm{Rd}$ inhibit the growth of HT29 cells through activation of apoptosis processes. ${ }^{29}$ A previous study in HCT116 colon cancer cells demonstrated that Rh2 induced apoptosis through activation of $\mathrm{p} 53 .^{30}$

For the detection of apoptosis in MCF7 breast cancer cells, relative gene expressions of p53 and the cleaved CASP3, 7, 9 were evaluated through Western blot analysis (Figure 8). Activation of CASP7 and CASP9 pathways has 

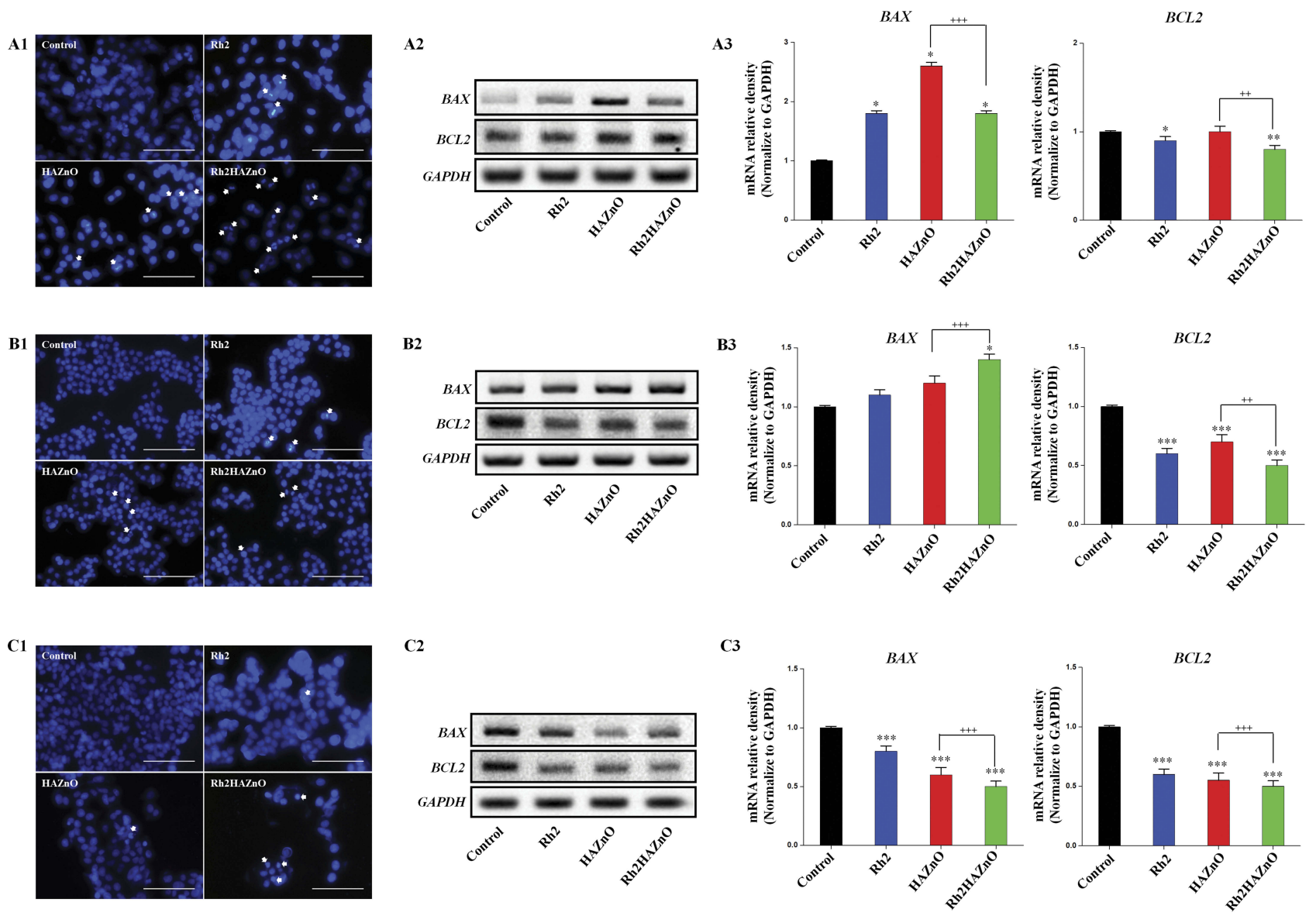

Figure 5 Evaluation of apoptosis in three cancer cell lines.

Notes: Cells were treated with Rh2 (ginsenoside Rh2), HAZnO (hyaluronic acid zinc oxide nanoparticles) and Rh2HAZnO for 24 hrs. Hoechst stained positive apoptotic cells are indicated with white arrows $(\mathbf{A l}, \mathbf{B} \mathbf{I}$, and $\mathbf{C I}$ ). Scale bar $=10 \mu \mathrm{m}$. Relative gene expression was evaluated by RT-PCR (A2-C2 and A3-C3), and band density was analyzed with ImageJ software. (AI-A3) Lung cancer (A549). (B I-B3) Colon cancer (HT29). (CI-C3) Breast cancer (MCF-7). Each bar represents the mean \pm SE of duplicate samples of three independent experiments. ${ }^{*} P<0.05$, ${ }^{* *} P<0.01$, and ${ }^{* * * P}<0.001$ compared to the non-treated control. ${ }^{++} P<0.0 \mathrm{I}$, and ${ }^{+++} P<0.00 \mathrm{I}$ compared $\mathrm{HAZnO}$ with Rh2HAZnO. The difference was observed using Student's $t$-test.

been identified to play an essential role in apoptosis, especially during apoptotic chromatin condensation and DNA fragmentation in various cell lines. Furthermore, the anti-proliferative effect of $\mathrm{Rh} 2 \mathrm{HAZnO}$ has been found to be related to activation of p38 MAPK, CASP9 genes, p38 MAPK, and CASP9 proteins during treatment, as a result of the morphological changes in the nuclei of MCF7 cells along with the cytotoxic effect and induction of oxidative stress. The expression of p53 through Western blot analysis did not show increased p53 accumulation, indicating that MCF7 cells undergo apoptosis through activation of CASP7 and CASP9 rather than p53 itself (Figure 8B, C, and E)

The proposed mechanism of inducing apoptosis is illustrated in Figure 9. The cytotoxicity effect of Rh2HAZnO is postulated from triggering intracellular reactive oxygen species (ROS), which was observed in three different cancer cells (Figure 4). The photoluminescent effect of $\mathrm{ZnO}$ initiates electron transmission from the valence band to the conduction band, thus creating an electron-hole pair. The hole can induce a sequence of photochemical reactions to generate ROS at the NP surface in an aqueous suspension. ${ }^{70}$ ROS generation by ZnONPs upon irradiation with UV light has been utilized for photo-triggered anticancer and antibacterial activities via ROS-induced damage to cell membranes, mitochondria, proteins, and DNA. ${ }^{31}$ The tumor suppressor protein p53 is a redox-active transcription factor that organizes cellular responses upon a range of stresses including intracellular induction of ROS. ${ }^{32}$ The increase in intracellular ROS is associated with the magnitude of p53 protein expression, ${ }^{33}$ which was also shown in the lung cancer A549 cells (Figure 6D) and the colon cancer HT29 cells (Figure 7D) while the opposite trend was observed in the breast cancer MCF-7 cells (Figure 8D). 


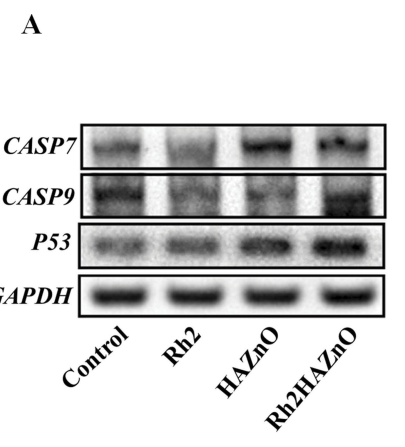

B

C

CASP9

D

$P 53$
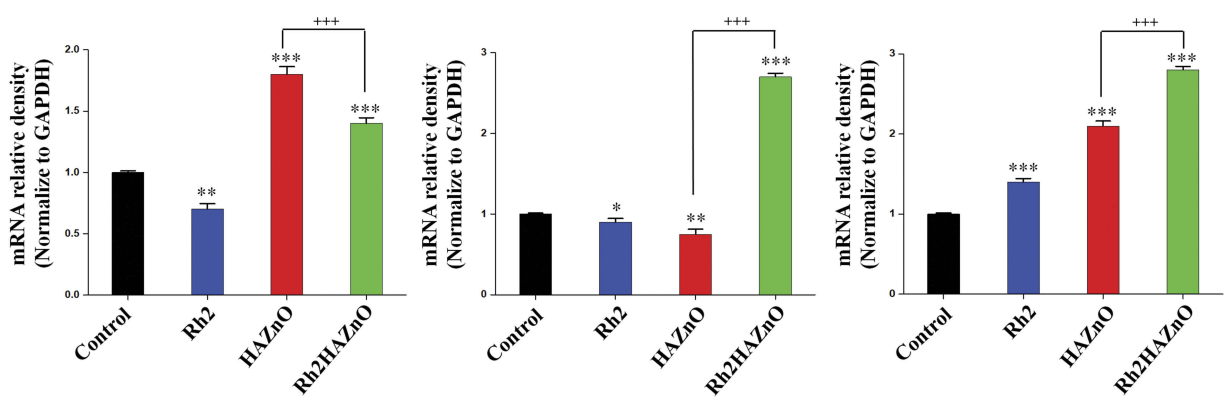

$\mathbf{E}$

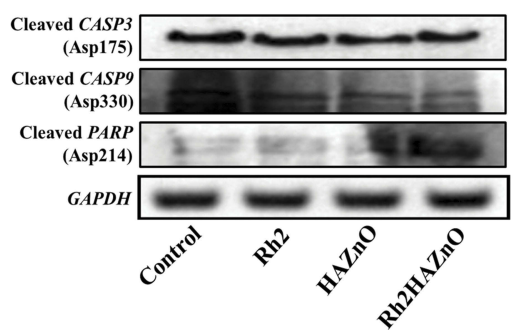

Figure 6 Potential apoptotic mechanism of Rh2HAZnO in A549 lung cancer cells.

Notes: Cells were treated with Rh2 (ginsenoside Rh2), HAZnO (hyaluronic acid zinc oxide nanoparticles) and Rh2HAZnO for 24 hrs (A). The relative analysis was analyzed with Image software (B-D). Protein expression was evaluated by Western blotting (E). Each bar represents the mean \pm SE of duplicate samples of three independent experiments. $* P<0.05$, $* * P<0.01$, and $* * * P<0.001$ compared to the non-treated control. ${ }^{+++} P<0.001$ compared $\mathrm{HAZnO}$ with Rh2HAZnO. The difference was observed using Student's $t$-test.

A

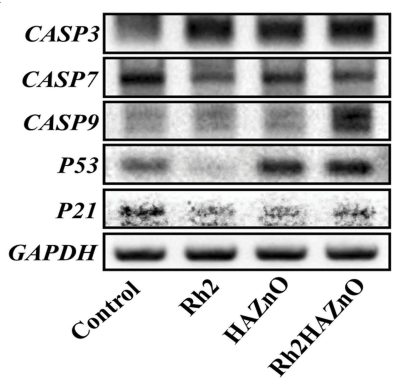

B

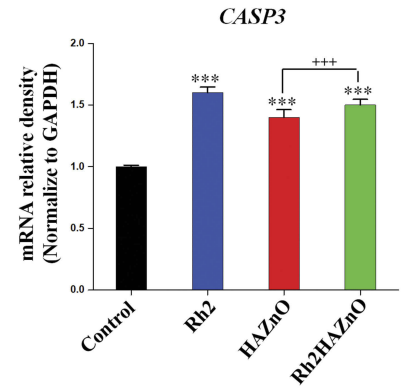

$\mathbf{E}$

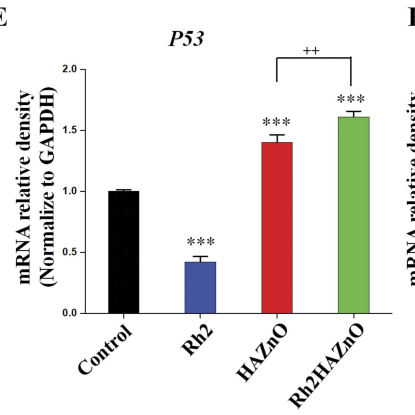

C

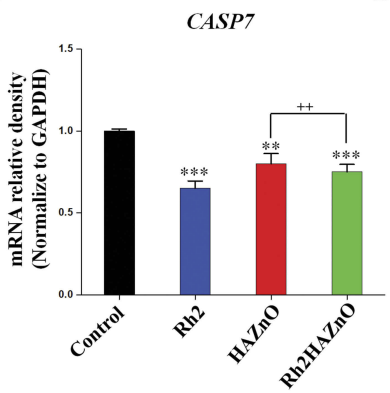

F

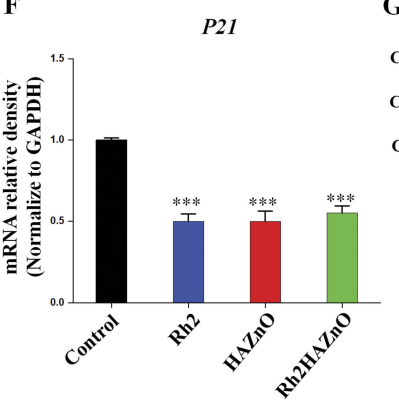

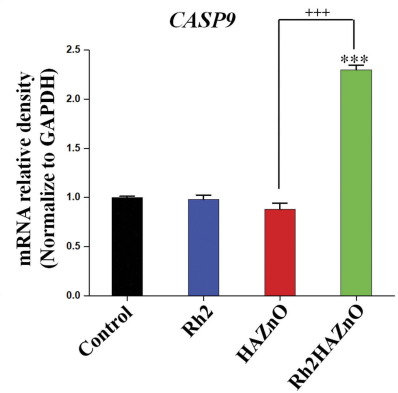

G

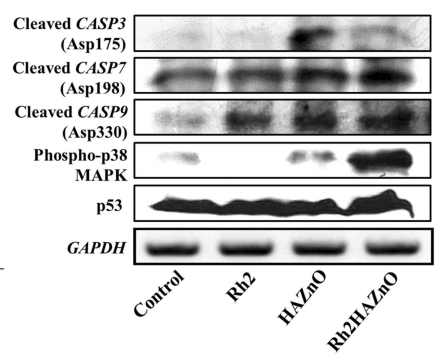

Figure 7 Potential apoptotic mechanism of Rh2HAZnO in HT29 colon cancer cells.

Notes: Cells were treated with Rh2 (ginsenoside Rh2), HAZnO (hyaluronic acid zinc oxide nanoparticles) and Rh2HAZnO for 24 hrs. Relative gene expression was evaluated by RT-PCR (A), and band density analysis was done with Image software (B-F). Protein expression was evaluated by Western blotting (G). Each bar represents the mean $\pm \mathrm{SE}$ of duplicate samples of three independent experiments. $* * P<0.01$, and ${ }^{* * *} P<0.001$ compared to the non-treated control. ${ }^{++} P<0.0 \mathrm{I}$, and ${ }^{+++} P<0.00 \mathrm{I}$ compared $\mathrm{HAZnO}$ with Rh2HAZnO. The difference was observed using Student's $t$-test.

The increasing ratio $\mathrm{BAX} / \mathrm{Bcl}-2$ results in the formation of apoptosome and activation of its effector, CASP9, ${ }^{34,35}$ which was indicated as the increased transcriptional expression of CASP9 in A549, HT29, and MCF-7 cancer cells 

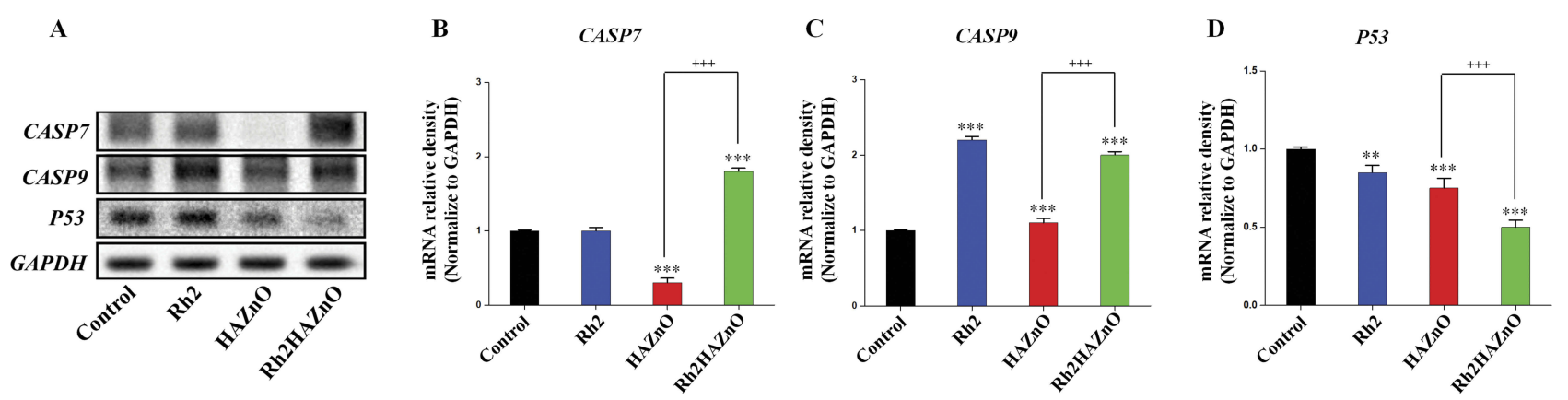

$\mathbf{E}$

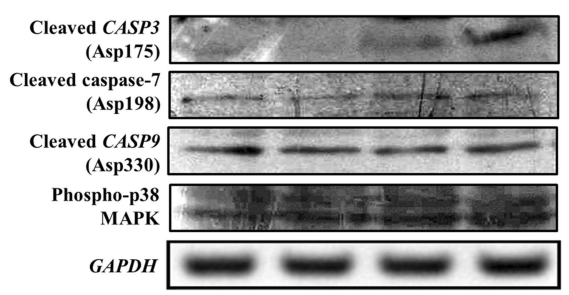

Figure 8 Potential apoptotic mechanism of Rh2HAZnO in MCF-7 breast cancer cells.

Notes: Cells were treated with Rh2 (ginsenoside Rh2), HAZnO (hyaluronic acid zinc oxide nanoparticles) and Rh2HAZnO for 24 hrs. Relative gene expression was evaluated by RT-PCR $(\mathbf{A})$, band density analysis was analyzed with Imagej software (B-D). Protein expression was evaluated by Western blotting (E). Each bar represents the mean $\pm \mathrm{SE}$ of duplicate samples of three independent experiments. ${ }^{* * P}<0.0 \mathrm{I}$, and ${ }^{* * *} \mathrm{P}<0.00 \mathrm{I}$ compared to the non-treated control. ${ }^{+++} P<0.00 \mathrm{I}$ compared $\mathrm{HAZnO}$ with Rh2HAZnO. The difference was observed using Student's $t$-test.

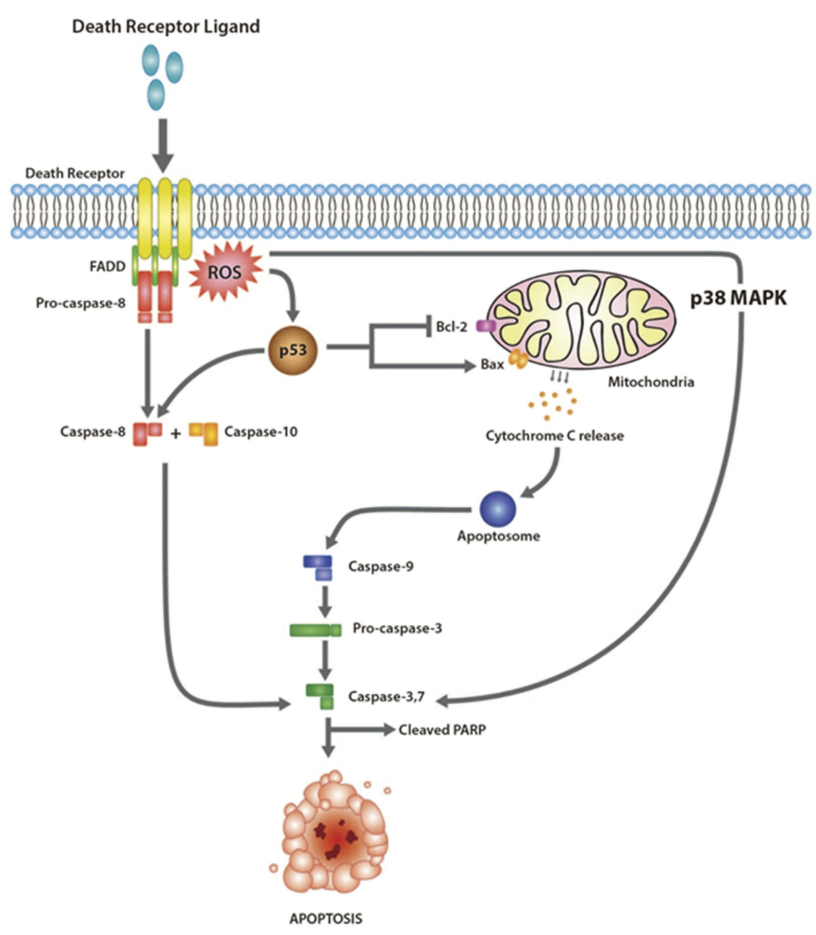

Figure 9 The proposed mechanism of the apoptotic effect of Rh2HAZnO on the three different cancer cells: A549 (lung), HT29 (colon), and MCF7 (breast) cancer cells.

(Figures 6C, 7D, and 8C). The activation of CASP9 contributed to the activation of CASP7 in MCF-7 cells (Figure 8B). Since CASP7 is one of the two effectors of mitochondrial events of apoptosis, ${ }^{36,37}$ the series of expressional change of apoptosis-related proteins indicated that the ROS stress induced by $\mathrm{Rh} 2 \mathrm{HAZnO}$ results in mitochondria-mediated apoptosis. This postulation was also confirmed with an increase of cleaved PARP in the HT29 colon cancer cells.

Our data for the first time showed that Rh2HAZnO inhibits the proliferation of cancer cells by inducing apoptotic-mediated cell death. This result suggests that Rh2HAZnO might serve as a potential antitumor agent against various cancer cells with further proper in vivo experimental analysis.

\section{Conclusion}

In this study, we evaluate the potential of Rh2HAZnO to induce apoptosis and DNA damage in lung cancer (A549), colon cancer (HT29), and breast cancer (MCF7) cells, respectively. It has been identified that, among different caspase pathways, activation of the caspase-9 pathway is required for apoptosis by $\mathrm{Rh} 2 \mathrm{HAZnO}$. Furthermore, the effects of Rh2HAZnO on Caspase-9/p38 MAPK markers were elucidated for anticancer activity.

\section{Acknowledgments}

This work was supported by a grant from the Basic Science Research Program through the National Research Foundation of Korea funded by the Ministry of Education (2019R1A2C1010428) and NG-BioGreen 
21 program (SSAC, PJ0128132019), the Rural Development Administration, Republic of Korea.

\section{Author Contributions}

YJK, HP and VC carried the experiment and wrote the paper. DK and DCY analyzed the results based on the key pathway for the conclusive description in the manuscript. JM and YL carried out the production of HAZnRh2 nanoparticles. SL and SK carried out analysis of photoluminescent data and cell image. All authors contributed to data analysis, drafting or revising the article, gave final approval of the version to be published, and agreed to be accountable for all aspects of the work.

\section{Disclosure}

The authors report no conflicts of interest in this work.

\section{References}

1. World Health Organization. Global health observatory data repository. 2011. Number of deaths (World) by cause. 2017.

2. Thun MJ, DeLancey JO, Center MM, Jemal A, Ward EM. The global burden of cancer: priorities for prevention. Carcinogenesis. 2009;31 (1):100-110. doi:10.1093/carcin/bgp263

3. Coseri S. Natural products and their analogues as efficient anticancer drugs. Mini Rev Med Chem. 2009;9(5):560-571. doi:10.2174/ 138955709788167592

4. Hartshorn CM, Bradbury MS, Lanza GM, et al. Nanotechnology strategies to advance outcomes in clinical cancer care. ACS Nano. 2018;12(1):24-43. doi:10.1021/acsnano.7b05108

5. Wang R, Billone PS, Mullett WM. Nanomedicine in action: an overview of cancer nanomedicine on the market and in clinical trials. $J$ Nanomater. 2013;2013:1. doi:10.1155/2013/625739

6. You Q, Sun Q, Yu M, et al. BSA-bioinspired gadolinium hybridfunctionalized hollow gold nanoshells for NIRF/PA/CT/MR quadmodal diagnostic imaging-guided photothermal/photodynamic cancer therapy. ACS Appl Mater Interfaces. 2017;9(46):40017-40030. doi:10.1021/acsami.7b11926

7. Aditya A, Chattopadhyay S, Gupta N, et al. ZnO nanoparticles modified with an amphipathic peptide show improved photoprotection in skin. ACS Appl Mater Interfaces. 2018;11(1):56-72. doi:10.1021/acsami.8b08431

8. Sirelkhatim A, Mahmud S, Seeni A, et al. Review on zinc oxide nanoparticles: antibacterial activity and toxicity mechanism. Nano Micro Lett. 2015;7(3):219-242. doi:10.1007/s40820-015-0040-x

9. Kim DH. Gut microbiota-mediated pharmacokinetics of ginseng saponins. J Ginseng Res. 2018;42(3):255-263. doi:10.1016/j.jgr.2017.04.011

10. Wong AS, Che C-M, Leung K-W. Recent advances in ginseng as cancer therapeutics: a functional and mechanistic overview. Nat Prod Rep. 2015;32(2):256-272. doi:10.1039/c4np00080c

11. Mathiyalagan R, Kim YJ, Wang C, et al. Protopanaxadiol aglycone ginsenoside-polyethylene glycol conjugates: synthesis, physicochemical characterizations, and in vitro studies. Artif Cells Nanomed Biotechnol. 2016;44(8):1803-1809. doi:10.3109/21691401.2015.1105236

12. Markus J, Mathiyalagan R, Kim YJ, et al. Synthesis of hyaluronic acid and O-carboxymethyl chitosan-stabilized $\mathrm{ZnO}$-ginsenoside $\mathrm{Rh} 2$ nanocomposites incorporated with aqueous leaf extract of dendropanax morbifera léveille: in vitro studies as potential sunscreen agents. New J Chem. 2019. doi:10.1039/C8NJ06044D
13. Zhou J, Xu NS, Wang ZL. Dissolving behavior and stability of ZnO wires in biofluids: a study on biodegradability and biocompatibility of $\mathrm{ZnO}$ nanostructures. Adv Mater. 2006;18(18):2432-+. doi:10.1002/adma.200600200

14. Xu F, Zhang P, Navrotsky A, et al. Hierarchically assembled porous $\mathrm{ZnO}$ nanoparticles: synthesis, surface energy, and photocatalytic activity. Chem Mater. 2007;19(23):5680-5686. doi:10.1021/cm071190g

15. Wang C, Mathiyalagan R, Kim YJ, et al. Rapid green synthesis of silver and gold nanoparticles using Dendropanax morbifera leaf extract and their anticancer activities. Int $J$ Nanomedicine. 2016;11:3691. doi:10.2147/IJN.S97181

16. Kim Y-J, Perumalsamy H, Markus J, et al. Development of Lactobacillus kimchicus DCY51T-mediated gold nanoparticles for delivery of ginsenoside compound $\mathrm{K}$ : in vitro photothermal effects and apoptosis detection in cancer cells. Artif Cells Nanomed Biotechnol. 2019;47(1):30-44. doi:10.1080/21691401.2018.1541900

17. Kovács D, Igaz N, Keskeny C, et al. Silver nanoparticles defeat p53positive and p53-negative osteosarcoma cells by triggering mitochondrial stress and apoptosis. Sci Rep Uk. 2016;6:27902. doi:10.1038/ srep27902

18. Dhillon AS, Hagan S, Rath O, Kolch W. MAP kinase signalling pathways in cancer. Oncogene. 2007;26(22):3279. doi:10.1038/sj.onc.1210421

19. Kim S, Shin DH, Kim J, et al. Energy transfer from an individual silica nanoparticle to graphene quantum dots and resulting enhancement of photodetector responsivity. Sci Rep Uk. 2016;6:27145.

20. Fang L, Cheng Q, Bai J, et al. An oncolytic adenovirus expressing interleukin-24 enhances antitumor activities in combination with paclitaxel in breast cancer cells. Mol Med Rep. 2013;8(5):14161424. doi: $10.3892 / \mathrm{mmr} .2013 .1680$

21. Sosa V, Moliné T, Somoza R, Paciucci R, Kondoh H, LLeonart ME. Oxidative stress and cancer: an overview. Ageing Res Rev. 2013;12 (1):376-390. doi:10.1016/j.arr.2012.10.004

22. Wang B, Zhang YY, Mao ZW, Yu DH, Gao CY. Toxicity of ZnO nanoparticles to macrophages due to cell uptake and intracellular release of zinc ions. J Nanosci Nanotechno. 2014;14(8):5688-5696. doi:10.1166/jnn.2014.8876

23. Chen T, Chen $\mathrm{H}$, Wang $\mathrm{Y}$, Zhang J. In vitro and in vivo antitumour activities of puerarin 6 "-O-xyloside on human lung carcinoma A549 cell line via the induction of the mitochondria-mediated apoptosis pathway. Pharm Biol. 2016;54(9):1793-1799. doi:10.3109/138802 09.2015.1127980

24. Chen L, Gong M-W, Peng Z-F, et al. The marine fungal metabolite, dicitrinone B, induces A375 cell apoptosis through the ROS-related caspase pathway. Mar Drugs. 2014;12(4):1939-1958. doi:10.3390/ md12041939

25. Deng J. How to unleash mitochondrial apoptotic blockades to kill cancers? Acta Pharm Sin B. 2017;7(1):18-26. doi:10.1016/j.apsb. 2016.08.005

26. Yuan Z, Jiang H, Zhu X, Liu X, Li J. Ginsenoside Rg3 promotes cytotoxicity of Paclitaxel through inhibiting NF- $\mathrm{BB}$ signaling and regulating $\mathrm{Bax} / \mathrm{Bcl}-2$ expression on triple-negative breast cancer. Biomed Pharm. 2017;89:227-232. doi:10.1016/j.biopha.2017.02.038

27. Wang Y, Xu H, Lu Z, et al. Pseudo-Ginsenoside Rh2 induces A549 cells apoptosis via the Ras/Raf/ERK/p53 pathway. Exp Ther Med. 2018;15(6):4916-4924. doi:10.3892/etm.2018.6067

28. Yuan H-D, Quan H-Y, Zhang Y, Kim SH, Chung S-H. 20 (S)Ginsenoside Rg3-induced apoptosis in HT-29 colon cancer cells is associated with AMPK signaling pathway. Mol Med Rep. 2010;3 (5):825-831. doi:10.3892/mmr.2010.328

29. Lee SY, Kim GT, Roh SH, et al. Proteome changes related to the anticancer activity of HT29 cells by the treatment of ginsenoside Rd. Die Pharmazie Int J Pharm Sci. 2009;64(4):242-247.

30. King M, Murphy L. Role of cyclin inhibitor protein $\mathrm{p} 21$ in the inhibition of HCT116 human colon cancer cell proliferation by American ginseng (Panax quinquefolius) and its constituents. Phytomedicine. 2010;17(34):261-268. doi:10.1016/j.phymed.2009.06.008 
31. Zhang HJ, Chen BA, Jiang H, Wang CL, Wang HP, Wang XM. A strategy for $\mathrm{ZnO}$ nanorod mediated multi-mode cancer treatment. Biomaterials. 2011;32(7):1906-1914. doi:10.1016/j.biomaterials.20 10.11.027

32. Smiles W, Camera D. The guardian of the genome p53 regulates exercise-induced mitochondrial plasticity beyond organelle biogenesis. Acta Physiologica. 2018;222(3):e13004. doi:10.1111/apha.12 884

33. Macip S, Igarashi M, Berggren P, Yu J, Lee SW, Aaronson SA. Influence of induced reactive oxygen species in p53-mediated cell fate decisions. Mol Cell Biol. 2003;23(23):8576-8585. doi:10.1128/ mcb.23.23.8576-8585.2003
34. Guo -X-X, Guo Q, Li Y, Lee S, Wei X-N, Jin Y-H. Ginsenoside rh2 induces human hepatoma cell apoptosisvia bax/bak triggered cytochrome $\mathrm{C}$ release and caspase-9/caspase-8 activation. Int J Mol Sci. 2012;13(12):15523-15535. doi:10.3390/ijms131215523

35. Renatus M, Stennicke HR, Scott FL, Liddington RC, Salvesen GS. Dimer formation drives the activation of the cell death protease caspase 9. Proc Natl Acad Sci. 2001;98(25):14250-14255. doi:10.1073/pnas.231465798

36. Wolan DW, Zorn JA, Gray DC, Wells JA. Small-molecule activators of a proenzyme. Science. 2009;326(5954):853-858. doi:10.1126/ science. 1177585

37. Riedl SJ, Salvesen GS. The apoptosome: signalling platform of cell death. Nat Rev Mol Cell Biol. 2007;8(5):405. doi:10.1038/nrm2153

\section{Publish your work in this journal}

The International Journal of Nanomedicine is an international, peerreviewed journal focusing on the application of nanotechnology in diagnostics, therapeutics, and drug delivery systems throughout the biomedical field. This journal is indexed on PubMed Central, MedLine, CAS, SciSearch ${ }^{\mathbb{R}}$, Current Contents ${ }^{\mathbb{R}} /$ Clinical Medicine, $^{-}$
Journal Citation Reports/Science Edition, EMBase, Scopus and the Elsevier Bibliographic databases. The manuscript management system is completely online and includes a very quick and fair peer-review system, which is all easy to use. Visit http://www.dovepress.com/ testimonials.php to read real quotes from published authors. 